\title{
Tadalafil in the treatment of erectile dysfunction
}

\author{
Robert M Coward \\ Culley C Carson \\ Division of Urologic Surgery, \\ University of North Carolina, Chapel \\ Hill, NC, USA
}

\begin{abstract}
The treatment for erectile dysfunction (ED) was revolutionized with the development of phosphodiesterase type 5 (PDE5) inhibitors. Tadalafil (Cialis ${ }^{\circledR}$; Eli Lilly and Company, Indianapolis, IN, USA) is the newest and most versatile PDE5 inhibitor in the clinical armamentarium for the treatment of ED. Its most unique characteristic is its long half-life of 17.5 hours, which lends itself to a longer therapeutic window with on-demand dosing and effective steadystate plasma concentrations with once-daily dosing. Clinical trials have proven its safety and efficacy with both dosing strategies for all severities and etiologies of ED, including difficultto-treat ED. This thorough review will discuss ED, the physiology of penile erection and the role of PDE5, and all aspects of tadalafil, from its development, through its pharmacology, to its latest clinical studies and indications.
\end{abstract}

Keywords: tadalafil, Cialis, PDE5 inhibitors, phosphodiesterase type 5, erectile dysfunction, penile erection

\section{Introduction}

Attempts at determining the neurotransmitter or neurotransmitters involved in creating an erection may some day lead to successful nonhormonal medical therapy [for erectile dysfunction] (Krane 1986, p. 731).

— Robert J Krane, MD, in Campbell's Urology, Fifth Edition

The last two decades have seen a dramatic growth of understanding in the physiology of erection, the pathophysiology of erectile dysfunction (ED), and its treatment options. As the above quote from the fifth edition of Campbell's Urology reveals, it was not long ago when little was known of erectile physiology, and adequate treatment was still "some day" away. Prior to the turn of the century, the pharmacologic treatment options for ED were cumbersome and invasive, limited to intracavernosal injections or intraurethral pellets. Everything changed when oral phosphodiesterase type 5 (PDE5) inhibitors became available, completely revolutionizing the treatment of ED of all severities and etiologies. Pfizer introduced the first PDE5 inhibitor, sildenafil (Viagra ${ }^{\circledR}$; Pfizer, New York, NY, USA), in March of 1998, and over the past 10 years, the new oral pharmacologic therapy together with an unbridled acceptance and newfound candor by the general public has not only dramatically increased the awareness and prevalence of ED, but also made treatment of the disease simple and effective. Once one of the most frustrating and refractory diseases for the urologic specialist, ED is now enthusiastically discussed and treated in the primary care setting.

The addition of two more PDE5 inhibitors to the market in 2003 broadened the landscape of ED treatment and solidified PDE5 inhibitors as safe and effective first-line treatments for ED. With the development of the new PDE5 inhibitors, attention was focused on increased potency as well as duration of action. Tadalafil (Cialis ${ }^{\circledR}$; Eli Lilly and Company, Indianapolis, IN, USA), the newest of the three available PDE5 inhibitors, is similar to sildenafil and vardenafil (Levitra ${ }^{\circledR}$; Bayer AG, Germany) in its mechanism of action, but differs primarily in its longer duration of action. In January 2008, 
Eli Lilly announced the latest innovation in the treatment of ED, Federal Drug Administration (FDA) approval for tadalafil once-daily dosing in the treatment of ED.

In this review, we will highlight ED, the physiology of penile erection, and the role of PDE5 before focusing on the newest and most versatile PDE5 inhibitor. We intend to thoroughly report tadalafil's pharmacology, safety, and drug interactions; its efficacy, indications, and clinical trials; and its favorability by patients and partners. The reasons why tadalafil is a distinct, efficacious, and favorable treatment in the clinical armamentarium for the treatment of ED will be clear at the conclusion of this review.

\section{Erectile dysfunction}

ED is the inability to achieve and maintain an erection sufficient to permit satisfactory sexual intercourse (NIH 1993). Affecting 150 million men worldwide, ED is growing rapidly, and its prevalence is expected to double to greater than 300 million men worldwide over the next 20 years (McKinlay 2000). According to data extrapolated from the Massachusetts Male Aging Study, the incidence of ED is increasing at an astronomical rate, with an expected incidence of over 600,000 new cases per year in white men aged 40 to 69 alone (Johannes et al 2000). Despite its growing incidence, which is partly a result of the sexual awakening stimulated by the new pharmacologic therapies, ED remains underdiagnosed, with millions of men worldwide never coming to medical attention because of the sensitivity of the issue.

The pathophysiology of ED has a variety of etiologies including psychological, hormonal, neurogenic, vasculogenic, drug-induced, or cavernosal impairment from any of the aforementioned factors (Lue 2000). The etiologies are frequently categorized into psychogenic, organic (hormonal, neurogenic, vasculogenic, drug-induced, and cavernosal impairment), or the most common type of ED which is a mixed psychogenic and organic type (Lue 2000).

The pharmacologic evolution that has occurred over the past several decades has directed the current understanding of the pathophysiology of the disease process. Until the 1980s, the treatment options were limited to psychosexual therapy and placement of penile implants, and through that time it was believed that ED was primarily due to psychogenic causes. With the introduction of prostaglandin intracavernosal injections in the late 1980s, the vasculogenic etiologies of ED became better understood, and the connection between late onset hypogonadism and ED led to research elucidating the hormonal etiologies of the condition (Kaminetsky 2008). Finally, the new oral treatment with PDE5 inhibitors has led to the current understanding of the pathophysiology of ED as well as the physiology of erection.

\section{The physiology of erection and the role of phosphodiesterase type 5}

A penile erection is a transformation of erectile tissue and vasculature from a state of minimally-perfused flaccidity into an engorged state. It is mediated by a multifaceted succession of neural and vascular components, coupled with hormonal and psychological factors. Through complex neural pathways consisting of somatic sensory afferent (pudendal) and autonomic (cavernous) nerves, as well as supraspinal structures including the medial preoptic area and paraventricular nucleus of the hypothalamus, sexual arousal stimulates the release of neurotransmitters that initiate erection (Carson and Lue 2005).

The primary erectile-mediating neurotransmitter is nitric oxide (NO), a short-lived, gaseous mediator. NO is synthesized in nonadrenergic, noncholinergic fashion by neuronal nitric oxide synthase (nNOS) in the cavernous nerves to initiate erection and by endothelial nitric oxide synthase (eNOS) in the endothelium to maintain erection during sexual stimulation (Hurt et al 2002). NO passively crosses the cell membrane and activates soluble guanylyl cyclase (sGC) upon entering smooth muscle cytoplasm, which in turn increases the production of cyclic guanosine monophosphate (cGMP) by converting it from guanosine triphosphate (GTP) (Lincoln and Cornwell 1991). The increased concentration of cGMP activates protein kinase $\mathrm{G}$, also called cGMP-dependent kinase, which through phosphorylation of ion channels opens potassium channels and inhibits calcium channels. The resultant decrease in cytosolic calcium concentration favors smooth muscle relaxation (Dean and Lue 2005).

The vascular smooth muscle relaxation simultaneously vasodilates arterioles and trabecular smooth muscle sinusoids within erectile tissue to increase penile blood flow. Subsequently, compression of the subtunical venules against the tunica albuginea occludes venous outflow. During the final phase of rigid erection, robust contraction of the ischiocavernous muscles constricts the base of the blood-filled corpora cavernosa, causing the penis to become even harder. Arterial inflow and venous outflow are temporarily occluded during this phase, and the intracavernous pressure can approach several hundred millimeters of mercury (Lue 2000).

Detumescence results from sympathetic discharge with ejaculation, as well as at the molecular level with the cessation of NO release from the endothelium and the 
breakdown of cGMP and other secondary messengers by various phosphodiesterase (PDE) enzymes (Lue 2000). PDE is an enzyme that 50 years ago was discovered to block the activity of the second messenger cyclic adenosine 3',5'-monophosphate (cAMP) in animal models (Sutherland and Rall 1958). The PDE superfamily includes 11 families, PDE1 to PDE11, on 21 unique genes (Lin et al 2003). They are distributed throughout various tissues, primarily in vascular, visceral, and pulmonary smooth muscle, and they regulate physiologic functions in multiple organ systems (Carson and Lue 2005). In the penis, PDE acts to breakdown cGMP. Despite the observation that every family of PDE except PDE6 has been found in the corpus cavernosum, PDE5 is the most abundant PDE family in the penis (Carson 2007). By inhibiting the breakdown of cGMP, PDE5 inhibitors create increased bioavailability of cGMP, which both facilitates and potentiates the NO-mediated relaxation of erectile smooth muscle with sexual stimulation.

Caffeine and theophylline were two of the first drugs found to inhibit the PDE enzyme decades ago (Butcher and Sutherland 1962). Over the past 30 years, inhibitors of several families of PDE have been developed to treat a number of diseases. These include the PDE3 inhibitors milrinone and amrinone developed in the 1980s for heart failure, a PDE4 inhibitor cilostazol developed for claudication, and the anti-platelet drug dipyridamole that inhibits PDE8, PDE9, and PDE5 (Carson and Lue 2005). Papaverine was the first PDE inhibitor used in the treatment of ED, and it is still used in practice today. Administered as an intracorporal injection, papaverine is a non-selective inhibitor of PDE3 and its isoforms (Carson 2007). Originally investigated as a treatment for angina pectoris, the first oral PDE5 inhibitor, sildenafil, was fortuitously discovered to produce erections in study participants. It was later released in 1998 as the first oral treatment for ED, and this was followed in 2003 by the release of two more PDE5 inhibitors, vardenafil and tadalafil.

\section{History of the development of tadalafil}

The Bothell, Washington-based pharmacologic research company ICOS Corporation was started in 1990, and it began the initial cardiovascular testing of a PDE5 inhibitor called IC351 in 1993. Meanwhile, sildenafil citrate (sildenafil) was discovered to cause improved erectile function as a side effect in a trial testing its efficacy for the treatment of angina pectoris in 1994. IC351 was patented that year, and phase I clinical trials began in 1995. Two years later, phase II clinical trials began on patients with ED.
The same year that the FDA approved sildenafil as the first PDE5 inhibitor for the treatment of ED, Eli Lilly and Company joined the ICOS Corporation to form Lilly ICOS LLC in 1998 to expand the marketing venture of the newest PDE5 inhibitor. Tadalafil was officially born in the year 2000 when a new drug application was put forth for IC351 with the generic name tadalafil and trade name Cialis.

In May 2002, the first reports regarding the efficacy and duration of action of tadalafil for ED were presented at the 97th Annual Meeting of the American Urological Association (AUA) in Orlando, Florida, USA. Brock and colleagues presented their initial data supporting the efficacy and safety of tadalafil (Brock et al 2002b), and Porst and colleagues presented that tadalafil is efficacious for up to 36 hours (Porst et al 2002). Brock's data were published later that year in a landmark integrative analysis of five randomized controlled trials of tadalafil that ultimately led to the approval of the drug (Brock et al 2002a). Tadalafil was approved for use in Europe in late 2002, and on November 21, 2003, tadalafil was approved by the FDA for use in the United States.

\section{Tadalafil pharmacology}

The three available PDE5 inhibitors share a similar mechanism of action, but they have structural, pharmacologic, and clinical differences. The molecular structure of tadalafil is available in Figure 1. Tadalafil's molecular structure is different than the similar structures of sildenafil and vardenafil. All three have a heterocyclic nitrogen-containing doublering system, with a central ring that is analogous to that of cGMP and allows for competitive binding of the drug with

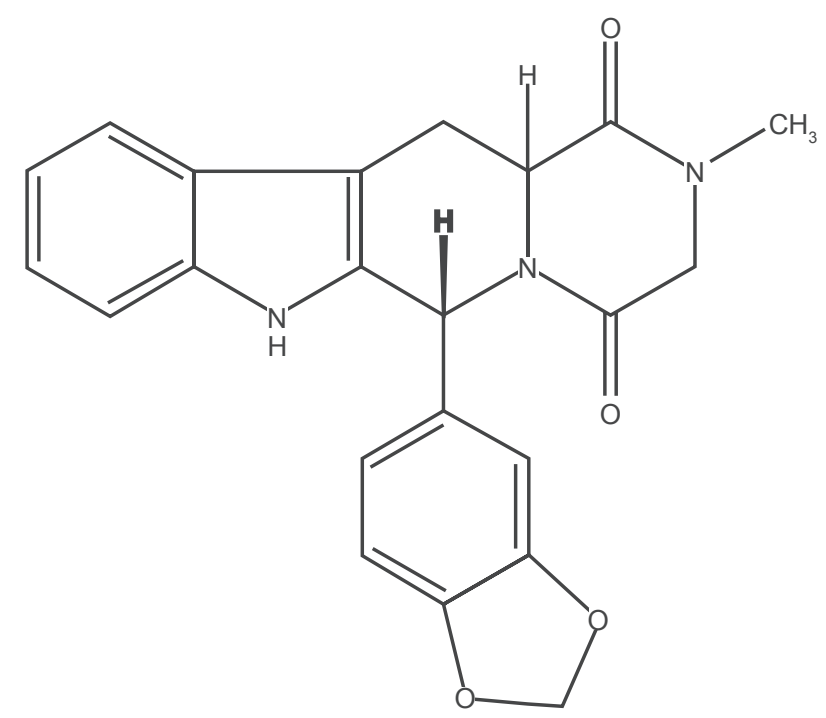

Figure I Molecular structure of tadalafil. 
PDE5 at the catalytic site (Francis et al 2001). Tadalafil is different in that it is a $\beta$-carboline-type PDE5 inhibitor with a piperazinedione ring formed from a modification of the hydantoin ring of sildenafil (Francis et al 2001).

\section{Phosphodiesterase selectivity}

Tadalafil is at least 9000 times more selective for PDE5 than most of the other families of PDEs, with the exception of PDE11 (Briganti et al 2005). PDE11 is found in the testes and prostate; however, despite partial inhibition of PDE11 by tadalafil at therapeutic doses, clinical significance of this observation has yet to be fully understood (ICOS 2008). A study by Hellstrom and colleagues concluded that there are no harmful effects of tadalafil on spermatogenesis or testicular function (Hellstrom et al 2003).

The PDE enzyme responsible for phototransduction in the retina, PDE6, is inhibited to some degree by sildenafil and vardenafil, but not tadalafil. The inhibition of PDE6 explains the side effect of blue vision experienced by some patients with these two drugs, as PDE6 inhibition in the retina causes impairment of blue-green color discrimination (Carson 2007). Slightly less common with vardenafil, altered vision is a reported side effect for $11 \%$ of men taking sildenafil $100 \mathrm{mg}$ (Montorsi et al 1999). Compared with sildenafil and vardenafil, tadalafil is much less inhibitory for PDE6, and it is over 700 times more potent for PDE5 than PDE6 (ICOS 2008). For this reason, tadalafil has less than $0.1 \%$ occurrence of vision abnormalities (Brock et al 2002; Carson et al 2004a).

\section{Dosing and absorption}

Recommended starting doses of tadalafil are $10 \mathrm{mg}$ for on-demand dosing and $2.5 \mathrm{mg}$ for once-daily dosing, and these doses can then be titrated up or down according to the efficacy and tolerability (ICOS 2008). It is absorbed as a low-solubility and high-permeability, or Class 2, drug within the FDA Biopharmaceuticals Classification System (Gupta et al 2005). With oral ingestion, after first-pass metabolism, tadalafil is approximately $80 \%$ bioavailable, compared to $40 \%$ and $15 \%$ with sildenafil and vardenafil, respectively (Francis and Corbin 2003). Tadalafil has the slowest absorption of the available PDE5 inhibitors with a mean of 2 hours to reach its maximum concentration, compared with about 50 minutes for sildenafil and vardenafil (Briganti et al 2005). The onset of action of tadalafil may occur in as early as 15 minutes of dosing, although successful erections occur in fewer than $40 \%$ of men at this time point (Brock et al 2002; Porst et al 2003). It is not advisable to counsel patients that the drug effect may be seen in as early as 15 minutes because it may take up to 2 hours for a response in the majority of men. This may only create performance anxiety or loss of confidence in the treatment, leading to treatment failure (Carson 2007).

Differences in gastrointestinal absorption with fatty meals explain the varying peak plasma concentration $\left(\mathrm{T}_{\max }\right)$ among the three PDE5 inhibitors (Corbin and Francis 2002). While sildenafil and vardenafil both have decreased absorption when taken with a fatty meal, which may increase the rate of treatment failure, the absorption of tadalafil is unaffected by fatty meals or alcohol consumption (Francis and Corbin 2003). This unique pharmacokinetic trait for tadalafil is a result of slower absorption and longer half-life, and it can therefore be taken with meals or alcohol without a decrease in efficacy (Carson 2007).

\section{Duration of action}

Among the three PDE5 inhibitors, the half-life and thus duration of action is the pharmacologic parameter that is the most strikingly dissimilar. The half-life of tadalafil is 17.5 hours in normal healthy men and 21.6 hours in elderly men, while the half-lives of sildenafil and vardenafil are similar at 4 hours (Francis and Corbin 2003). This longer half-life provides a therapeutic window of 36 hours for tadalafil (Porst et al 2003).

The risks of a longer half-life have yet to be completely elucidated, but there does not appear to be any higher mortality with tadalafil compared to the other PDE5 inhibitors. One difference resulting from the half-life disparity is that emergent treatment with nitrate medications must be deferred for at least 48 hours after ingestion of tadalafil, compared with 24 hours for sildenafil and vardenafil (Kloner et al 2003a).

Pharmacologic treatments for ED prior to tadalafil, including prostaglandin intracavernosal injections or intraurethral pellets, as well as the other two PDE5 inhibitors, all have a short half-life. For this reason, historically it has been necessary for ED treatments to be dosed immediately prior to attempting intercourse. A drawback to this necessary dosing schedule for short half-life ED treatments is potential performance anxiety. The therapeutic window of 36 hours of tadalafil allows the patient more freedom to choose the timing and setting of the sexual encounter with his partner.

Other benefits of tadalafil's longer half-life are still being explored. The FDA recently expanded the indications for tadalafil to once-daily dosing for the treatment of ED. The longer half-life provides a steady state of serum drug concentration with low dose, once-daily administration, a benefit not shared with the other two PDE5 inhibitors (McMahon 2004; 
McMahon 2005; Porst et al 2006; Porst et al 2008; Rajfer et al 2007).

\section{Metabolism and excretion}

The metabolism of tadalafil is via the hepatic enzyme cytochrome P450 34A (CYP34A) to a catechol metabolite, which undergoes further metabolism to its primary circulating metabolite, methylcatechol glucuronide, a 10,000-fold less potent molecule than tadalafil (Gupta et al 2005). The CYP34A metabolism pathway of tadalafil was verified with studies using a CYP34A inhibitor ketoconazole and a CYP34A inducer rifampin (Kostis et al 2005). Tadalafil is excreted largely as metabolites, approximately two-thirds into the feces and one-third into the urine (ICOS 2008).

\section{Adverse events}

A large study of 2102 men from 11 different multicentered, randomized, double-blind, placebo controlled trials of tadalafil reported the drug is well tolerated overall (Carson et al 2004a). Fifty-one percent of men using tadalafil $20 \mathrm{mg}$ had at least one adverse event (AE), but only $3.2 \%$ discontinued treatment. The most common AEs reported with the $20 \mathrm{mg}$ dose were headache $(15 \%)$, dyspepsia $(8 \%)$, and back pain (5\%) (Table 1) (Carson et al 2004a). Most AEs are a result of vasodilation of vascular beds other than in the penis.

Although frequently asked about by patients, priapism is rarely associated with PDE5 inhibitors. Several case reports have found an extraordinarily uncommon link between sildenafil and priapism, and only a single case report exists in the literature implicating tadalafil with priapism (King et al 2005). PDE5 inhibitors including tadalafil may actually have some benefit in preventing recurrent, or stuttering, priapism. A small series of 4 men with stuttering priapism were administered daily PDE5 inhibitors, one case of which used tadalafil, and all four men had decreases in priapism recurrences (Burnett et al 2006).

\section{Safety and drug interactions}

As with every PDE5 inhibitor, tadalafil is absolutely contraindicated with nitrate medications for angina pectoris secondary to the potentiated hypotensive effect the drugs can have together. Because of the longer half-life, treatment with nitrate medications must be deferred for at least 48 hours after ingestion of tadalafil, compared with 24 hours for sildenafil and vardenafil (Kloner et al 2003a).

The cardiac effects of PDE5 inhibitors have received considerable attention because the drugs were originally studied as a treatment for angina pectoris secondary to their action of smooth muscle relaxation. All of the PDE5 inhibitor trials have tediously monitored study participants' vital signs, particularly heart rate and blood pressure, monitored drug effects on cardiac electrophysiology, and tabulated the numbers of cardiovascular adverse events (Carson 2005).

In a review of more than 4000 patients from over 60 studies, data reported by Kloner and co-workers contended that tadalafil does cause small changes in blood pressure secondary to its vasodilatory properties, but that the changes were not clinically meaningful (Kloner et al 2003b). In a separate, more recent study, the same author retrospectively reviewed serious cardiovascular treatment-emergent adverse events reported in 36 tadalafil trials and found that the incidence of these events were comparable among patients taking tadalafil

Table I Most common tadalafil treatment-emergent adverse events

\begin{tabular}{llll}
\hline Safety variable & Placebo $(\mathbf{n}=\mathbf{6 3 8})$ & Tadalafil I $\mathbf{~ m g}(\mathbf{n}=\mathbf{3 2}$ I $)$ & Tadalafil 20 $\mathbf{~ m g}(\mathbf{n}=\mathbf{I}$ | 43) \\
\hline Subjects with $\geq$ I treatment emergent AE & $247(39 \%)$ & $185(58 \%)$ & $577(5$ I\%) \\
Discontinuation for AE & $8(1.3 \%)$ & $5(1.6 \%)$ & $36(3.2 \%)$ \\
Most common treatment emergent AEs & & & $173(15 \%)$ \\
Headache & $30(5 \%)$ & $38(12 \%)$ & $90(8 \%)$ \\
Dyspepsia & $7(1 \%)$ & $23(7 \%)$ & $60(5 \%)$ \\
Back pain & $15(2 \%)$ & $20(6 \%)$ & $23(2 \%)$ \\
Nasopharyngitis & $24(4 \%)$ & $26(8 \%)$ & $33(3 \%)$ \\
Myalgia & $6(1 \%)$ & $16(5 \%)$ & $39(3 \%)$ \\
Flushing & $8(1 \%)$ & $10(3 \%)$ & $28(2 \%)$ \\
Nasal congestion & $4(1 \%)$ & $11(3 \%)$ & $31(3 \%)$ \\
Pain in limb & $5(1 \%)$ & $10(3 \%)$ & \\
\hline
\end{tabular}

Data from an integrated analysis of 2102 patients in II randomized, double-blind, placebo-controlled trials. Adapted with permission from Carson CC, Rajfer J, Eardley I, et al 2004a. The efficacy and safety of tadalafil: an update. BJU Int, 93:I276-8I. Copyright (C) 2004 Wiley-Blackwell.

Abbreviation: $A E$, adverse events. 
as needed, 3 times per week, once-daily, and placebo (Kloner et al 2006).

The Second Princeton Consensus Conference, an expert conference on sexual dysfunction and cardiac risk, convened in 2004 to develop practice guidelines for the management of ED in patients with significant cardiac risk. After reviewing all available literature, the Second Princeton Consensus Conference not only determined that patients with significant cardiac risk factors did not exhibit worsening ischemia or unstable hemodynamics while taking PDE5 inhibitors, but also that cardiovascular function was actually improved by PDE5 inhibitors in some studies (Kostis et al 2005). Although reported with vardenafil, prolongation of the $\mathrm{QT}_{\mathrm{c}}$ interval is not observed with tadalafil (Kloner 2004).

Tadalafil does not cause increased hypotension or orthostatic hypotension in men that are also taking multiple antihypertensive medications, and it is safe and well tolerated in this population (Kloner et al 2003c). The primary exception is with $\alpha$-blockers. Frequently prescribed for men with benign prostatic hyperplasia (BPH) as well as for men with hypertension, $\alpha$-blockers share a similar mechanism of action with PDE5 inhibitors through peripheral vasodilation and may have more of an additive effect than other antihypertensives. Recently, the FDA changed its previous recommendation from contraindicated co-administration to precautionary co-administration (Kostis et al 2005). In a study of the blood pressure effects of tadalafil coupled with either of two $\alpha$-blockers, doxazosin (Cardura ${ }^{\circledR}$; Pfizer, New York, NY, USA) and tamsulosin (Flomax ${ }^{\circledR}$; Boehringer Ingelheim, Ridgefield, CT, USA), the hypotensive effect of doxazosin was exaggerated by almost $10 \mathrm{mmHg}$ with tadalafil while there was no change in blood pressure with tamsulosin and tadalafil (Kloner et al 2004). The authors concluded tamsulosin to be a safe $\alpha$-blocker to administer concurrently with tadalafil (Kloner et al 2004). Until more studies are available, precaution is recommended with the co-administration of tadalafil with any $\alpha$-blocker, including mixed $\alpha$-blockers such as labetalol and carvedilol (Kostis et al 2005; ICOS 2008).

Because of its metabolism through the cytochrome P450 pathway, tadalafil is susceptible to changes in serum concentration by other drugs that inhibit or promote its metabolism. Inhibitors of the CYP34A enzyme include ketoconazole, erythromycin, grapefruit juice, and protease inhibitors, and co-administration of these drugs with tadalafil may increase serum concentrations of tadalafil. On the contrary, co-administration with inducers of CYP34A including rifampin, carbamazepine, phenytoin, and phenobarbital, would require a larger dose of tadalafil for a similar clinical effect (Kostis et al 2005).

\section{Efficacy}

Tadalafil is an efficacious treatment for ED of all severities and etiologies. The largest data series exist for the general ED population with mild to moderate ED (Brock et al 2002a; Carson et al 2004a), but tadalafil has also been shown to be an effective treatment for difficult-to-treat ED such as more severe, organic ED evaluated in tertiary care centers (Carson et al 2005a), ED secondary to diabetes mellitus (Saenz de Tejada et al 2002; Fonseca et al 2004), and ED resulting from prostate cancer treatments such as prostatectomy (Montorsi et al 2004; Carson et al 2005b) and radiotherapy (Incrocci et al 2007).

Several recent studies have shown a significant treatment benefit from once-daily, low-dose tadalafil (McMahon 2004; McMahon 2005; Porst et al 2006; Rajfer et al 2007; Hatzichristou et al 2008; Porst et al 2008). These studies have lead to the most recent development in the treatment of ED, once-daily tadalafil for ED, which was FDA-approved in 2008 .

\section{Background on outcome measures}

Although the effectiveness of PDE5 inhibitors on such intermediate objective outcomes as penile rigidity through penile plethysmography with the RigiScan device (Dacomed Corporation, Minneapolis, MN, USA) has been studied, measuring the therapeutic effectiveness of tadalafil is more accurately defined through an integration of the patient's reported treatment response and tolerability with the reported satisfaction of both the patient and his partner (Carson et al 2004b). Despite their intrinsically subjective nature, validated questionnaires are the preferred major outcome measure of treatment effectiveness of tadalafil and other PDE5 inhibitors.

The International Index of Erectile Function (IIEF) was developed by Rosen and colleagues in 1997 as a multidimensional, 15-item, self-administered questionnaire with the goal of assessing five domains of male sexual function including erectile function, orgasmic function, sexual desire, intercourse satisfaction, and overall satisfaction (Rosen et al 1997). The erectile function domain of the IIEF (IIEF-EF) contains 6 questions which the patient answers on a scale from 1 (never or almost never) to 5 (almost always or always), providing a total score of 6 to 30 points. The questions concern erectile frequency, firmness, penetration ability, 
maintenance frequency, maintenance ability, and erection confidence (Rosen et al 1997). Based on a controlled study of 1151 men taking sildenafil in order to establish cutoff scores for the IIEF-EF, a score of 26 or greater is defined as normal function, mild ED is a score from 22 to 25 , mild to moderate ED 17 to 21, moderate ED 11 to 16, and severe ED 6 to 10 (Cappelleri et al 1999).

The Sexual Encounter Profile (SEP) is a patient diary that has a series of questions that the patient answers after each sexual encounter. The second question in the SEP diary (SEP-Q2) is a measure of penetration, "Were you able to insert your penis into your partner's vagina?" The third question of the SEP (SEP-Q3) is a true measure of successful intercourse, "Did your erection last long enough for you to have successful intercourse?" In tadalafil trials including data analyses of the SEP, the SEP-Q2 and SEP-Q3 are most often reported.

Less often but still occasionally reported in the literature is the Erectile Dysfunction Inventory of Treatment Satisfaction (EDITS) score, which more reliably assesses the patient and his partner's satisfaction with ED treatments and explores the impact of patient and partner satisfaction on treatment continuation (Althof et al 1999). Graded on a scale of 1 to 100 , a score of 50 or higher indicates treatment satisfaction (Carson and Lue 2005).

In addition to the IIEF and the SEP, many tadalafil trials report a global overall assessment as provided by the patient, known as a Global Assessment Question (GAQ). It is a summary question to assess global improvement and to provide an indirect estimate of patient satisfaction. A frequently reported GAQ in tadalafil trials is, "Did the treatment improve your erections?"

\section{The general ED population}

The most frequently referenced study supporting the efficacy of tadalafil is an integrated analysis of 5 randomized, doubleblind, placebo controlled, multicentered phase III trials from 1112 men at 74 centers worldwide (Brock et al 2002a). The average age was 59 , and the etiology of ED was $61 \%$ organic, $9 \%$ psychogenic, and $31 \%$ mixed. The ED severity at baseline was mild in $41 \%$, moderate in $23 \%$, and severe in $36 \%$. Subjects were randomized to placebo or tadalafil at doses from $2.5 \mathrm{mg}$ to $20 \mathrm{mg}$ and instructed to self-administer a dose before initiating intercourse up to once daily. IIEF-EF, SEP, and GAQ scores were assessed at baseline and at 12 weeks (Brock et al 2002a).

Results of the integrated analysis found all doses of tadalafil to enhance efficacy outcomes (Brock et al 2002a).
The IIEF-EF at the end of treatment increased by 6.5 in men receiving tadalafil $10 \mathrm{mg}$ and by 7.9 with the $20 \mathrm{mg}$ dose, compared with 0.6 in men receiving placebo $(\mathrm{p}<0.001)$. Successful intercourse attempts were increased in $34 \%$ of men with a $10 \mathrm{mg}$ dose and $39 \%$ with a $20 \mathrm{mg}$ dose versus a $6 \%$ improvement in the placebo group when the SEP-Q3 answers were compared after 12 weeks $(\mathrm{p}<0.001)$. Tadalafil remained efficacious up to 36 hours, as more than $70 \%$ of attempts were successful from 30 minutes to 36 hours after dosing. On the GAQ, $81 \%$ of men reported improved erections overall with tadalafil $20 \mathrm{mg}$ compared with $35 \%$ in the placebo group $(\mathrm{p}<0.001)$. The percentage of men receiving a $20 \mathrm{mg}$ dose of tadalafil who had complete resolution of ED as defined by an IIEF-EF of 26 or higher was $59 \%$, compared with only $11 \%$ with placebo (Brock et al 2002a).

In an update to Brock and colleagues' study, Carson and associates performed another integrated analysis on all available tadalafil trials, including the original 1112 men in the 5 trials from Brock and colleagues' original study, plus an additional 1215 men from 6 more recently completed trials (Carson et al 2004a). The same study design, safety measures, and statistical analysis were performed, except patients who received $2.5 \mathrm{mg}$ and $5 \mathrm{mg}$ doses in two of the earlier studies that were included in the analysis by Brock and colleagues were not included by Carson and associates. Only doses of $10 \mathrm{mg}$ and $20 \mathrm{mg}$ of tadalafil were compared with placebo. The average age was 56, and the etiology of ED was 58\% organic, $12 \%$ psychogenic, and $31 \%$ mixed. The ED severity at baseline was mild in $36 \%$, moderate in $27 \%$, and severe in $33 \%$. Comorbidities included $29 \%$ of men with hypertension, $16 \%$ with hyperlipidemia, 20\% with diabetes mellitus, and $5 \%$ with coronary artery disease (Carson et al 2004a).

The results from the IIEF-EF, SEP-Q2, and SEP-Q3 are summarized in Figure 2. There were robust mean improvements in the IIEF-EF score, with increases of 6.5 points with $10 \mathrm{mg}$ of tadalafil and 8.6 points with the $20 \mathrm{mg}$ dose, versus only 0.9 points in the placebo group $(\mathrm{p}<0.001)$ (Carson et al 2004a). According to the SEP-Q3, successful intercourse attempts were improved by $34 \%$ to a total of $58 \%$ with $10 \mathrm{mg}$ tadalafil, and a $46 \%$ improvement to a total of $68 \%$ was seen with the $20 \mathrm{mg}$ dose, compared with an $8 \%$ improvement to a $31 \%$ total with placebo ( $\mathrm{p}<0.001)$. When successful intercourse attempts with tadalafil $20 \mathrm{mg}$ were stratified by time after dosing, tadalafil remained almost equally efficacious at 36 hours. At the endpoint of the trial using the GAQ, 71\% and $84 \%$ of patients reported overall improved erections with the two doses of tadalafil, respectively, compared with 33\% with placebo $(\mathrm{p}<0.001)$ (Carson et al 2004a). This second 

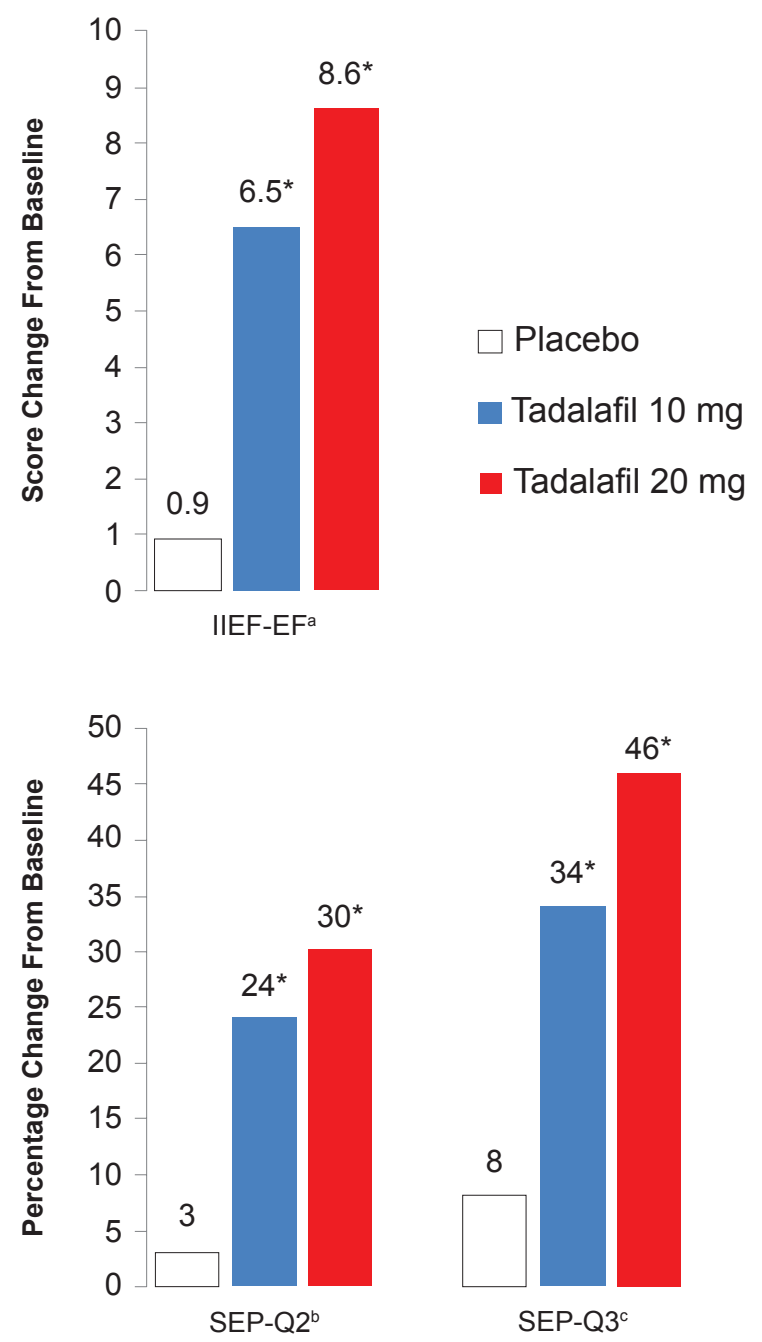

Figure 2 IIEF-EF, SEP-Q2, and SEP-Q3 improvements from baseline to 12 weeks with on-demand tadalafil.

aErectile function domain score of the International Index of Erectile Function. bQuestion 2 from the Sexual Encounter Profile diary, "Were you able to insert your penis into your partner's vagina?"

'Question 3 from the Sexual Encounter Profile diary, "Did your erection last long enough for you to have successful intercourse?"

${ }^{*} \mathrm{p}<0.00 \mathrm{I}$ versus placebo.

Data from an integrated analysis of 2102 patients in II randomized, double-blind, placebo-controlled trials.Adapted with permission from Carson CC, Rajfer J, Eardley I, et al 2004a.The efficacy and safety of tadalafil:an update. BJU Int, 93: I 276-8I. Copyright (c) 2004 Wiley-Blackwell.

integrated analysis of 11 tadalafil trials concluded that tadalafil is a very effective and well tolerated treatment for ED of all severities and etiologies in men of all ages in the general population.

\section{Difficult-to-treat ED}

In the two trials mentioned in the previous section, the patient population was largely a primary care population of relatively healthy men with ED of varying severities and etiologies. To the contrary, a multicentered, randomized, double-blind, placebo controlled trial evaluated how tadalafil $20 \mathrm{mg}$ improved ED in men presenting to tertiary care centers with more severe, organic ED and with more comorbid medical conditions than previous studies (Carson et al 2005a).

One hundred and ninety-five men were allocated to receive tadalafil $20 \mathrm{mg}$ or placebo up to once daily for 12 weeks with simplified dosing instructions (Carson et al 2005a). Efficacy was assessed using the IIEF-EF, the SEP, and a GAQ, and the EDITS was provided at the end of the trial to assess satisfaction of the patient and his partner. The mean baseline IIEF-EF was 13 , with $33 \%$ of participants reporting mild $\mathrm{ED}, 23 \%$ with moderate $\mathrm{ED}$, and $51 \%$ with severe ED at baseline. Organic ED predominated with $81 \%$, followed by $3 \%$ of men with psychogenic $\mathrm{ED}$, and $16 \%$ with mixed type. Comorbidities included $41 \%$ with hypertension, $36 \%$ with hyperlipidemia, $21 \%$ with diabetes mellitus, and $8 \%$ with coronary artery disease (Carson et al 2005a).

Tadalafil $20 \mathrm{mg}$ improved the IIEF-EF by 6.9 compared with -0.2 in the placebo group ( $p<0.001$ ), improved successful intercourse attempts by $34 \%$ compared with $4.5 \%$ in the placebo group $(p<0.001)$, and $73 \%$ of patients in the tadalafil group reported improved erections on the GAQ compared with $15 \%$ in the placebo group $(\mathrm{p}<0.001)$. The overall EDITS score was 67 in the tadalafil group compared with 36 in the placebo group ( $<<0.001)$, and a significant correlation was observed between the scores of the patient and his partner, demonstrating improved satisfaction with parallel improvement in partner satisfaction. This study concluded that even in a tertiary care population of patients with a higher incidence of severe, organic ED and comorbid medical conditions, tadalafil remains a safe and well tolerated drug that significantly improves ED treatment satisfaction for patients and partners (Carson et al 2005a).

\section{ED secondary to diabetes mellitus}

ED is a common problem afflicting over a third of all men with diabetes mellitus type 2 , and diabetes is independently responsible for a 3- to 4-fold increase in the risk of ED according to a survey of 1460 diabetic men (De Barardis et al 2003). ED is strongly related to the severity of diabetes, with a higher incidence in patients with a long history of diabetes, patients using insulin, and patients with microvascular complications of diabetes (De Berardis et al 2003). Diabetic men with ED also have significantly worse disease-specific health-related quality of life (Penson et al 2003).

In the largest original, prospective trial of tadalafil in diabetic men, Sáenz de Tejada and co-workers reported that tadalafil significantly improves ED and is well tolerated 
in this population (Sáenz de Tejada et al 2002). A total of 216 men with type 1 or type 2 diabetes mellitus were randomized to placebo, tadalafil $10 \mathrm{mg}$, or tadalafil $20 \mathrm{mg}$ to be taken on-demand up to once daily for 12 weeks. The IIEF-EF, the SEP, and a GAQ were used to evaluate efficacy. The average age was 56, and the duration of diabetes was 12 years on average. Ninety-one percent of men had type 2 diabetes while $9 \%$ had type 1 diabetes, $22 \%$ had microvascular complications, and over $81 \%$ of men had poorly controlled diabetes with a hemoglobin $\mathrm{A}_{1 \mathrm{c}}$ of greater than 7.0\%. The baseline IIEF-EF was 12 , corresponding to moderate severity ED (Sáenz de Tejada et al 2002).

In diabetic men taking tadalafil $10 \mathrm{mg}$ or $20 \mathrm{mg}$, the IIEF-EF was improved by 6.4 and 7.3, respectively, compared with 0.1 with placebo $(\mathrm{p}<0.001$ ) (Sáenz de Tejada et al 2002). Successful intercourse was improved by $28 \%$ and $29 \%$ in the two tadalafil groups versus only $1.9 \%$ in the placebo group ( $p<0.001$ ). The GAQ revealed that only $25 \%$ of men in the placebo group felt they had improved erections, compared with $56 \%$ and $64 \%$ of men in the tadalafil $10 \mathrm{mg}$ and $20 \mathrm{mg}$ groups, respectively (p < 0.001) (Sáenz de Tejada et al 2002).

Results from a large, retrospective analysis of 12 randomized controlled trials of tadalafil including over 600 diabetic men parallels the data reported by Sáenz de Tejada (Fonseca et al 2004). The trials included in this retrospective analysis were many of the same trials analyzed in other integrated analyses reported here in this review. The average age was 57 , and diabetic men had more severe ED than patients without diabetes at baseline with a mean IIEF-EF of 12.6 compared to 15 in patients without diabetes $(\mathrm{p}<0.001)$. Comorbid conditions more common in the patients with diabetes included hypertension, hyperlipidemia, and coronary artery disease (Fonseca et al 2004).

Diabetic men in the tadalafil $10 \mathrm{mg}$ and $20 \mathrm{mg}$ groups had improvements of 6.2 and 7.4 in their IIEF-EF, respectively, versus 0.9 for placebo ( $p<0.001$ ) (Fonseca et al 2004). Successful intercourse was improved by $30 \%$ and $37 \%$ in the tadalafil $10 \mathrm{mg}$ and $20 \mathrm{mg}$ groups, respectively, compared with $4 \%$ in the placebo group $(\mathrm{p}<0.001)$. Overall, erections were reported as improved in $75 \%$ for the $20 \mathrm{mg}$ group, $61 \%$ for the $10 \mathrm{mg}$ group, and $30 \%$ for the placebo group (Fonseca et al 2004). According to these studies, ED secondary to diabetes is certainly amenable to treatment with tadalafil.

\section{ED after prostate cancer treatment}

All of the available prostate cancer treatments, including radical prostatectomy, external beam radiation therapy, brachytherapy, cryotherapy, androgen-deprivation therapy, and even active surveillance alone, can result in ED. ED after prostate cancer treatment includes both organic and psychogenic causes, as significant anxiety and depression may result from a diagnosis of prostate cancer, leading to psychogenic ED (Carson et al 2005b).

The most important risk for organic ED after prostate cancer treatment of any type is damage to the cavernosal nerves. Walsh first described the technique for sparing the bilateral neurovascular bundles to better preserve erectile function (Walsh et al 1983), and a bilateral nerve sparing radical prostatectomy (BNSRP) is the surgical standard for prostate cancer today. Approximately 155,000 prostatectomies were performed in the United States in 2005 according to hospital discharge data (DeFrances 2007). Potency in men after open BNSRP has a wide reported range of $10 \%$ to $97 \%$ in the literature (Talcott et al 1997; Stanford et al 2000; Walsh et al 2000; Menon et al 2005; Penson et al 2008). Of 1288 men who underwent radical prostatectomy as part of the Prostate Cancer Outcomes Study, only 28\% had erections sufficient for intercourse at 5 years (Penson et al 2008).

Cavernosal nerve injury during prostate cancer treatment is a neuropraxia resulting in atrophy of the cavernosal smooth muscle and abnormal deposition of collagen into the corpora cavernosa. Cavernosal hypoxia is another contributing factor in the development of fibrosis post-prostatectomy (Raina et al 2008). The smooth muscle atrophy and fibrosis leads to corporal veno-occlusive dysfunction (CVOD), which is recognized as the primary cause of organic ED after prostate cancer treatment (Rambhatla et al 2008).

There are increasing experimental data that increased concentrations of NO and cGMP have an antifibrotic effect on tissues including the tunica albuginea and corporal tissue, supporting a role for tadalafil to halt the pathophysiologic role of CVOD in post-prostate cancer treatment ED. Kovanecz and colleagues have recently studied the effect of once-daily tadalafil on the prevention of fibrosis and CVOD after cavernosal nerve injury in rats (Kovanecz et al 2007). Male rats had either a bilateral cavernosal nerve resection, unilateral cavernosal nerve resection, or a sham operation, and they were then either untreated or given once-daily tadalafil. CVOD was assessed at 45 days with cavernosometry and histopathology. The authors found that tadalafil normalized the increase in penile shaft collagen content, normalized the reduction in corporeal smooth muscle content, and improved the lower collagen type III:I ratio, effectively preventing CVOD and underlying corporal fibrosis after cavernosal nerve damage (Kovanecz et al 2008). Similarly, Vignozzi 
et al also found that once-daily tadalafil given to rats that have undergone bilateral cavernosal nerve resection reversed the decline in cavernosal smooth muscle to collagen ratio (Vignozzi et al 2006).

In the clinical arena, on-demand dosing of tadalafil has been studied for ED secondary to BNSRP and external-beam radiotherapy (Incrocci et al 2006; Montorsi et al 2004). Montorsi and associates evaluated on-demand dosing of tadalafil $20 \mathrm{mg}$ in men with ED following BNSRP in a randomized, double-blind, placebo controlled, multicentered study of 303 men over 12 weeks (Montorsi et al 2004). All men had normal erectile function preoperatively and had undergone a BNSRP 12 to 48 months prior to the study. Primary endpoints were IIEF-EF, SEP-Q2, and SEP-Q3, and secondary endpoints were the GAQ and the EDITS questionnaire. Average age was 60 years, and 93\% were white men. Almost two-thirds of the participants had some degree of postoperative tumescence at baseline as defined by reporting the ability "to achieve at least some erection" in over half of their sexual encounters on the SEP-Q1 (Montorsi et al 2004). Among all patients, $62 \%$ responded to tadalafil on the GAQ compared with $23 \%$ placebo ( $p<0.001$ ). Of those with some postoperative potency, $71 \%$ responded to tadalafil compared with $24 \%$ placebo ( $\mathrm{p}<0.001$ ). The SEP-Q3 revealed $41 \%$ of the total group had successful intercourse compared with $19 \%$ with placebo ( $\mathrm{p}<0.001$ ). Over $50 \%$ of men with residual function had successful intercourse compared with $26 \%$ placebo ( $\mathrm{p}<0.001$ ) (Montorsi et al 2004). In this trial, tadalafil was successful in producing erections sufficient for intercourse in men with ED after BNSRP, but it was more efficacious in men with some residual potency after surgery prior to treatment.

Sixty patients with ED after external-beam radiotherapy for prostate cancer were randomized to on-demand tadalafil $20 \mathrm{mg}$ or placebo in a double-blind, placebo controlled, crossover study lasting 12 weeks (Incrocci et al 2006). Efficacy was assessed with the IIEF-EF, SEP, and a GAQ. Average age was higher than most other tadalafil studies at 69 years, the participants' prostate cancer tumor stages were $37 \% \mathrm{~T} 1 \mathrm{c}, 37 \% \mathrm{~T} 2$, and $26 \% \mathrm{~T} 3$, and the baseline mean IIEF-EF score among all men revealed severe ED at 8.4. The IIEF-EF score improved to 17.7 with tadalafil and to 9.5 with placebo ( $\mathrm{p}<0.0001$ ). The SEP-Q3 data demonstrated $46 \%$ of participants successfully had intercourse with tadalafil $20 \mathrm{mg}$ compared with $12 \%$ with placebo ( $\mathrm{p}<0.0001$ ), and $67 \%$ of patients taking tadalafil $20 \mathrm{mg}$ responded positively with the GAQ compared with $20 \%$ with placebo $(\mathrm{p}<0.001)$ (Incrocci et al 2006). This study was continued as an openlabel extension over 6 weeks. Fifty-one of 60 patients $(85 \%)$ enrolled, who had a higher IIEF-EF score than those who did not enroll ( $p<0.05$ ). Tadalafil was equally effective in the double-blind phase as in the open-label phase of the study (Incrocci et al 2007).

Tadalafil and other PDE5 inhibitors dosed both in continuous fashion and on-demand have been proposed for erectile rehabilitation and ED prophylaxis after BNSRP. In a small, prospective, observational study of 27 patients who underwent BNSRP, tadalafil $20 \mathrm{mg}$ was dosed every 3 days beginning on the first postoperative day (Carson et al 2005b). At 6 weeks, $89 \%$ of men reported erections, and $50 \%$ had successful intercourse. One-hundred percent had erections at 6 months, with $78 \%$ reporting successful intercourse (Carson et al 2005b). Padma-Nathan and colleagues reported in a multicentered, placebo-controlled, prospective study of prophylactic sildenafil dosed nightly beginning 4 weeks after BNSRP and continuing for 36 weeks that patients taking prophylactic sildenafil had a $27 \%$ return of erectile function compared with only $4 \%$ in the placebo group $(\mathrm{p}<0.05)$ (Padma-Nathan et al 2008). A randomized, double-blind, multicentered study of early postoperative dosing with vardenafil, dosed either once-daily or on-demand and compared with placebo, in 628 men after BNSRP found that on-demand vardenafil treatment resulted in greater IIEF-EF scores and higher SEP-Q3 response rates than once-daily dosing or placebo (Montorsi et al 2008). Although the efficacy of postoperative treatment with PDE5 inhibitors to prevent CVOD and corporal fibrosis and reduce ED after BNSRP seems clear, it remains uncertain whether a continuous or an on-demand dosing strategy is superior in this setting.

\section{Once-daily dosing}

The latest innovation in the treatment of ED has arrived in the form of a simpler, once-daily dosing schedule for tadalafil, unlinking the temporal association of the medication and the sexual encounter. The unnatural process of taking a medication just prior to sex is a negative aspect of ED treatment for many patients (Hanson-Divers et al 1998). The 17.5 hour half-life of tadalafil lends itself to daily dosing because steady-state plasma concentrations are attained within five days of initiating daily dosing (Forgue et al 2006). Additionally, at steady-state concentration, the daily exposure is 1.6-fold greater than the same dose taken intermittently (Forgue et al 2006). Therefore, after 5 days of once-daily dosing, the plasma concentration of tadalafil achieved with a $2.5 \mathrm{mg}$ and $5 \mathrm{mg}$ dose is $4 \mathrm{mg}$ and $8 \mathrm{mg}$, respectively. The FDA announced approval for once-daily dosing of tadalafil 
in January 2008 after a thorough review of the studies outlined below.

McMahon has compared once-daily with on-demand dosing of tadalafil in two independent, open-label studies in Australian men with ED (McMahon 2004; McMahon 2005). In 112 men with ED who were previously unresponsive to on-demand tadalafil, once-daily tadalafil at flexible doses of $10 \mathrm{mg}$ and $20 \mathrm{mg}$ for 12 weeks was provided (McMahon 2004). Baseline IIEF-EF, SEP, and GAQ data were obtained from the cohort prior to any treatment with tadalafil and after the trial of on-demand tadalafil. Changes in the scores from both baselines were assessed after 12 weeks of daily dosing. Patients taking tadalafil $10 \mathrm{mg}$ once-daily improved the IIEF-EF score 12.8 from the no-treatment baseline and 8.2 from the on-demand treatment baseline $(p<0.001)$. Compared with $42 \%$ of men with on-demand tadalafil, $69 \%$ of men with once-daily tadalafil reported improved erections at the endpoint (McMahon 2004). McMahon then compared once-daily tadalafil $10 \mathrm{mg}$ with on-demand tadalafil $20 \mathrm{mg}$ in an open-label, parallel-arm, crossover study of 145 Australian men with ED (McMahon 2005). While both dosing strategies were efficacious, the once-daily dosing of tadalafil improved the IIEF-EF score by 11.9, compared to an improvement of 8.3 with the on-demand dosing $(\mathrm{p}<0.05)$. Additionally, compared with $30 \%$ at baseline, successful intercourse was reported in the SEP-Q3 in $69 \%$ and $84 \%$ of patients taking on-demand and once-daily tadalafil, respectively $(\mathrm{p}<0.05$ ). Overall, once-daily dosing was preferred by $72 \%$ of the patients (McMahon 2005).

The first multicentered, randomized, double-blind, placebo controlled study of once-daily tadalafil enrolled 268 men over 12 weeks and compared tadalafil $5 \mathrm{mg}$ and $10 \mathrm{mg}$ taken once-daily with placebo (Porst et al 2006). The study took place in 20 centers across Europe and South America in men with ED of all severities and etiologies. IIEF$\mathrm{EF}, \mathrm{SEP}$, and GAQ were assessed at baseline and at 12 weeks. The mean IIEF-EF change from baseline at the endpoint was 9.7 and 9.4 for tadalafil $5 \mathrm{mg}$ and tadalafil $10 \mathrm{mg}$, respectively, compared with 0.9 for placebo $(\mathrm{p}<0.001)$. Successful intercourse was achieved in $67.2 \%$ and $72.8 \%$, compared with $36.7 \%$ with placebo $(\mathrm{p}<0.001)$. The authors concluded once-daily tadalafil $5 \mathrm{mg}$ or $10 \mathrm{mg}$ significantly improved erectile function in men with ED (Porst et al 2006).

Rajfer and associates performed a similar study of once-daily tadalafil in American men with lower doses over a longer study duration (Rajfer et al 2007). Once-daily tadalafil $2.5 \mathrm{mg}, 5 \mathrm{mg}$, or placebo was dosed over a 24 week period in a randomized, double-blind, placebo controlled, parallel-design study in 287 men evaluated in 15 US centers. Primary endpoints included the change from baseline to 24 weeks in mean IIEF-EF score and the percentage of "yes" responses in SEP-Q2 and SEP-Q3. The IIEF-EF and SEP data are summarized in Figure 3. The IIEF-EF score had a mean improvement over 24 weeks of 6.0 and 7.0 in the tadalafil $2.5 \mathrm{mg}$ and $5 \mathrm{mg}$ groups, respectively, compared with $1.2 \mathrm{in}$ the placebo group ( $\mathrm{p}<0.001)$. Successful intercourse was improved over the 24 -week period in $31.2 \%$ and $35.1 \%$ in the tadalafil groups compared with $9.5 \%$ with placebo $(\mathrm{p}<0.001)$ (Rajfer et al 2007).
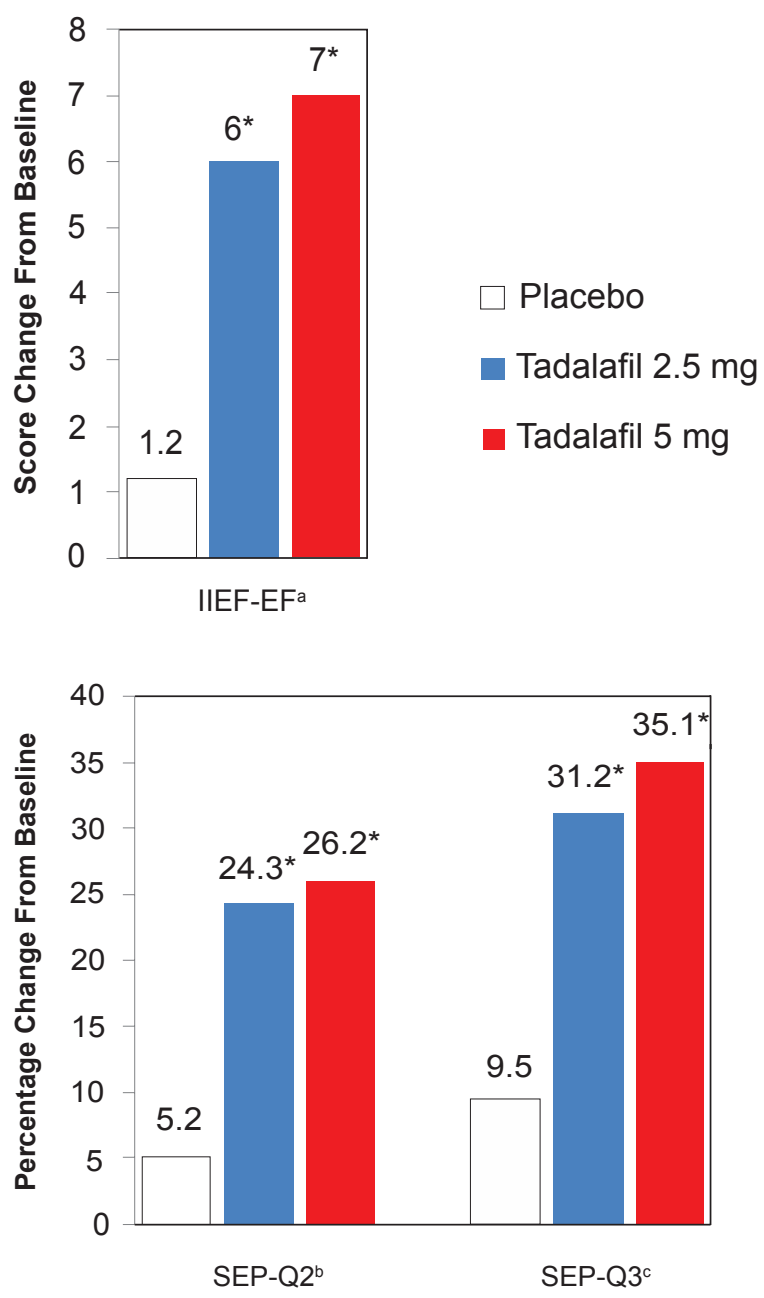

Figure 3 IIEF-EF, SEP-Q2, and SEP-Q3 improvements from baseline to 24 weeks with once-daily tadalafil.

${ }^{a}$ Erectile function domain score of the International Index of Erectile Function. bQuestion 2 from the Sexual Encounter Profile diary, "Were you able to insert your penis into your partner's vagina?"

'Question 3 from the Sexual Encounter Profile diary, "Did your erection last long enough for you to have successful intercourse?"

$*_{\mathrm{p}}<0.001$ versus placebo.

Data from a multicenter, randomized, double-blind, placebo-controlled study of 268 men to study once-daily tadalafil over 24 weeks.Adapted with permission from Rajfer J,Aliotta PJ, Steidle CP, et al 2007. Tadalafil dosed once a day in men with erectile dysfunction: a randomized, double-blind, placebo-controlled study in the US. Int J Impot Res, 19:95-103. Copyright @ 2007 Macmillan Publishers Ltd. 
In open-label extensions of the two randomized, placebo controlled trials of once-daily tadalafil described above, Porst and colleagues have evaluated the long-term safety and efficacy of once-daily tadalafil $5 \mathrm{mg}$ over 1 and 2 years (Porst et al 2008). There were 208 of 234 possible patients (88.9\%) who completed the 1-year extension and 139 of 238 possible patients (58.4\%) who completed the 2-year extension. Efficacy was measured by changes in the IIEF-EF score, SEP, and the GAQ. The IIEF-EF score improved from baseline by 10.4 and 10.8 in the 1- and 2-year extensions, respectively. After 2 years, $95.7 \%$ of patients reported improved erections (Porst et al 2008). Although an impressively positive response, the 2-year GAQ data had a significant dropout rate and likely contained selection bias toward patients who had a positive response.

Once-daily tadalafil has recently been studied in a population of men with ED secondary to diabetes mellitus (Hatzichristou et al 2008). A randomized, double-blind, placebo controlled, multicentered study in North America, Europe, and Australia enrolled 298 diabetic men with ED and randomized them to tadalafil $2.5 \mathrm{mg}, 5 \mathrm{mg}$, or placebo for 12 weeks. IIEF-EF, SEP, and GAQ were measured as primary outcomes. The mean age was $57,42.6 \%$ of patients had severe $\mathrm{ED}$, and comorbid conditions were prevalent and included $54 \%$ with hypertension and $43 \%$ with dyslipidemia. Eighty-nine percent of patients had diabetes mellitus type 2, average hemoglobin $\mathrm{A}_{1 \mathrm{c}}$ was $7.7 \%$, and glycemic control was good in $39 \%$, fair in $48 \%$, and poor in $13 \%$. Mean changes in IIEF-EF scores were modest, including 4.8 and 4.5 for the tadalafil $2.5 \mathrm{mg}$ and $5 \mathrm{mg}$ groups, respectively, compared with 1.3 for placebo $(p<0.005)$. Successful intercourse was improved by $25.9 \%$ and $25 \%$ in the tadalafil groups, versus $8.2 \%$ placebo $(\mathrm{p}<0.005)$. In this first study of once-daily tadalafil in diabetic men with ED, $2.5 \mathrm{mg}$ and $5 \mathrm{mg}$ once-daily both produced modest improvements in erectile function in this population (Hatzichristou et al 2008).

\section{New applications}

Recent data have indicated a potential association between epidemiological, physiologic, pathophysiologic, and treatment aspects of ED and lower urinary tract symptoms (LUTS) secondary to BPH (McVary and McKenna 2004). The 17.5 hour half-life of tadalafil makes it the most suitable PDE5 inhibitor for once-daily dosing in a trial of LUTS secondary to BPH. McVary and associates reported a multicentered, randomized, double-blind, placebo controlled study of 281 men with LUTS secondary to BPH who were randomly assigned to once-daily tadalafil $5 \mathrm{mg}$ for
6 weeks, followed by dose escalation to $20 \mathrm{mg}$ for 6 weeks, or 12 weeks of placebo. They reported modest decreases in International Prostate Symptom Score (IPSS), with a mean change from baseline to 6 weeks of -2.8 with tadalafil $5 \mathrm{mg}$ versus -1.2 with placebo $(\mathrm{p}<0.003)$, and to 12 weeks of -3.8 with tadalafil $5 / 20 \mathrm{mg}$ versus -1.7 with placebo $(\mathrm{p}<0.001)$ (McVary et al 2007).

To further examine the efficacy and dose response of tadalafil in men with LUTS secondary to BPH, Roehrborn and colleagues performed a similar multicentered, randomized, double-blind, placebo controlled study with a larger sample size and different tadalafil doses (Roehrborn et al 2008). The 1058 men with LUTS secondary to BPH in the study received once-daily placebo or tadalafil $(2.5,5,10$ or $20 \mathrm{mg}$ ) for 12 weeks. The IPSS mean change from baseline to endpoint after 12 weeks was significantly improved, -3.9 for tadalafil $2.5 \mathrm{mg}$ ( $\mathrm{p}<0.015),-4.9$ for tadalafil $5 \mathrm{mg}$ ( $\mathrm{p}<0.001),-5.2$ for tadalafil $10 \mathrm{mg}(\mathrm{p}<0.001)$, and -5.2 for tadalafil $20 \mathrm{mg}$ ( $p<0.001)$, compared with -2.3 for placebo. The optimal risk-benefit profile for men with LUTS secondary to BPH was achieved with the tadalafil $5 \mathrm{mg}$ dose (Roehrborn et al 2008).

These observations may be a result of increased cGMP causing a decrease in prostatic muscle tension (Uckert et al 2001), NO effect on the smooth muscle of the bladder, PDE inhibition in the prostate and prostatic urethra, or some other process not yet defined. Further basic science and clinical research is necessary to define the role of tadalafil's effect on the bladder, the prostate, and LUTS.

\section{Patient preference}

There have been several crossover trials that have attempted to compare patient and partner preference between sildenafil and tadalafil. Comparing the PDE5 inhibitors is intrinsically difficult because of the differences in dosing, absorption, duration of action, and other pharmacologic parameters (Carson and Lue 2005). Regardless, consensus results across multiple studies declare tadalafil as preferred over sildenafil by patients and their partners for the treatment of ED.

In a study to determine the proportion of current sildenafil users that would switch to tadalafil versus resume sildenafil after given a trial with tadalafil, 133 of 147 (90.5\%) patients elected to switch to tadalafil in the extension phase of the trial, irrespective of age group, severity of ED, or etiology of ED (Ströberg et al 2003). Prospective, randomized studies including over 750 men with various severities and etiologies of ED have found a preference for tadalafil over sildenafil by significant margins (Eardley et al 2005; Govier et al 2003; 
von Keitz et al 2004). A randomized, crossover study of 215 men with ED found $66.3 \%$ preferred tadalafil over sildenafil for initiation of ED therapy (Govier et al 2003). Another randomized, double-blind, crossover study comparing tadalafil with sildenafil reported that 132 of 181 (73\%) chose to receive tadalafil during the extension phase of the trial, irrespective of previous sildenafil use $(p<0.001)$ (von Keitz et al 2004). The results were even more disproportionate when stratified by other comorbid diseases. Men with diabetes had an $87 \%$ preference for tadalafil over sildenail ( $p<0.001$ ), and men with hypertension had a $79 \%$ preference for tadalafil ( $p<0.001$ ) (von Keitz et al 2004). The largest and most recent randomized, crossover, open-label study of sildenafil and tadalafil included 291 men naïve to PDE5 inhibitor therapy who were randomized to one drug for 12 weeks followed by the other for another 12 weeks, with a final 8-week extension phase during which time the patients chose their preferred agent (Eardley et al 2005). Efficacy of the two drugs was measured by IIEF-EF scores and a SEP diary. After completing both treatments, 71\% men chose tadalafil in the extension phase compared to $29 \%$ sildenafil ( $\mathrm{p}<0.001$ ). The IIEF-EF and SEP-Q2 were not significantly different, although the SEP-Q3 measuring successful intercourse was $77 \%$ with tadalafil compared with $72 \%$ with sildenafil $(\mathrm{p}<0.003)$ (Eardley et al 2005).

The Partner's Preference Study was a randomized, crossover study from a single center comparing tadalafil and sildenafil in 100 couples with the male partner having ED (Conaglen and Conaglen 2008). The couples were randomly assigned to tadalafil or sildenafil for 12 weeks followed by a second phase with 12 weeks of the alternate drug. Men and their partners completed SEP diaries, and the primary outcome data were the female partners' final interviews during which they provided their preference between the two drugs. Tadalafil was preferred by the female partner in $79.2 \%$, while $15.6 \%$ preferred sildenafil. The number of events recorded, timing of the events, and the number of doses were not significantly different between the groups. The female partners reported more relaxed, more satisfying, and longer-lasting sexual experiences with tadalafil as compared with sildenafil (Conaglen and Conaglen 2008).

\section{Conclusion}

Tadalafil is a safe, well tolerated, and efficacious treatment for all severities and etiologies of ED. Its efficacy has been proven in numerous clinical trials, and it is effective not only in the general ED population, but also the difficultto-treat ED population with more severe ED and a greater number of comorbidities. Its most unique characteristic is its long half-life of 17.5 hours, which lends itself to a longer therapeutic window with on-demand dosing and effective steady-state plasma concentrations with once-daily dosing. Taken on-demand or once-daily, tadalafil significantly enhances erectile function. Its newest indication for oncedaily dosing disconnects the temporal association of dosing a medication prior to the sexual encounter. These attributes make tadalafil a distinct, efficacious, and favorable treatment in the clinical armamentarium for the treatment of ED.

\section{Acknowledgments}

We would like to thank Harriet Ecclesine of Eli Lilly and Company for providing the molecular structure of tadalafil.

\section{Disclosures}

The authors have no conflicts of interest to declare.

\section{References}

Althof SE, Corty EW, Levine SB, et al. 1999. EDITS: development of questionnaires for evaluating satisfaction with treatments for erectile dysfunction. Urology, 53:793-9.

Briganti A, Salonia A, Gallina A, et al. 2005. Drug Insight: oral phosphodiesterase type 5 inhibitors for erectile dysfunction. Nat Clin Pract Urol, 2:239-47.

Burnett AL, Bivalacqua TJ, Champion HC, et al. 2006. Long-term oral phosphodiesterase 5 inhibitor therapy alleviates recurrent priapism. Urology, 67:1043-8.

Butcher RW, Sutherland EW. 1962. Adenosine 3',5'-phosphate in biological materials. I. Purification and properties of cyclic 30,50-nucleotide phosphodiesterase and use of this enzyme to characterize adenosine 3',5'-phosphate in human urine. J Biol Chem, 237:1244-50.

Brock GB, McMahon CG, Chen KK, et al. 2002a. Efficacy and safety of tadalafil for the treatment of erectile dysfunction: results of integrated analyses. $J$ Urol, 168:1332-6.

Brock G, McMahon C, Point P, et al. 2002b. Efficacy and safety of tadalafil in men with erectile dysfunction: an integrated analysis of registration trials [abstract]. $J$ Urol, 167:178.

Cappelleri JC, Rosen RC, Smith MD, et al. 1999. Diagnostic evaluation of the erectile function domain of the International Index of Erectile Function. Urology, 54:346-51.

Carson CC. 2005. Cardiac safety in clinical trials of phosphodiesterase 5 inhibitors. Am J Cardiol, $96: 37 \mathrm{M}-41 \mathrm{M}$.

Carson CC. 2007. Phosphodiesterase type 5 inhibitors: state of the therapeutic class. Urol Clin North Am, 34:507-15.

Carson CC, Giuliano F, Goldstein I, et al. 2004b. The 'effectiveness' scale - therapeutic outcome of pharmacologic therapies for ED: an international consensus panel report. Int J Impot Res, 16:207-13.

Carson CC, Hubbard JS, Wallen E. 2005b. Erectile dysfunction and treatment of carcinoma of the prostate. Curr Urol Rep, 6:461-9.

Carson CC, Lue TF. 2005. Phosphodiesterase type 5 inhibitors for erectile dysfunction. BJU Int, 96:257-80.

Carson CC, Rajfer J, Eardley I, et al. 2004a. The efficacy and safety of tadalafil: an update. BJU Int, 93:1276-81.

Carson CC, Shabsigh R, Segal S, et al. 2005a. Efficacy, safety, and treatment satisfaction of tadalafil versus placebo in patients with erectile dysfunction evaluated at tertiary-care academic centers. Urology, 65:353-9.

Conaglen HM, Conaglen JV. 2008. Investigating women's preference for sildenafil or tadalafil use by their partners with erectile dysfunction: the partners' preference study. $J$ Sex Med, 5:1198-207. 
Corbin JD, Francis SH. 2002. Pharmacology of phosphodiesterase-5 inhibitors. Int J Clin Pract, 56:453-9.

DeFrances CJ, Cullen KA, Kozak LJ. 2007. National Hospital Discharge Survey: 2005 annual summary with detailed diagnosis and procedure data. Vital Health Stat, 13:1-209.

De Berardis G, Pellegrini F, Franciosi M, et al. 2003. Identifying patients with type 2 diabetes with a higher likelihood of erectile dysfunction: the role of the interaction between clinical and psychological factors. J Urol, 169:1422-8.

Dean RC, Lue TF. 2005. Physiology of penile erection and pathophysiology of erectile dysfunction. Urol Clin North Am, 32:379-95.

Eardley I, Mirone V, Montorsi F, et al. 2005. An open-label, multicentre, randomized, crossover study comparing sildenafil citrate and tadalafil for treating erectile dysfunction in men naïve to phosphodiesterase 5 inhibitor therapy. BJU Int, 96:1323-32.

Francis SH, Corbin JD. 2003. Molecular mechanisms and pharmacokinetics of phosphodiesterase-5 antagonists. Curr Urol Rep, 4:457-65.

Francis SH, Turko IV, Corbin JD. 2001. Cyclic nucleotide phosphodiesterases: relating structure and function. Prog Nucleic Acid Res Mol Biol, 65:1-52.

Forgue ST, Patterson BE, Bedding AW, et al. 2006. Tadalafil pharmacokinetics in healthy subjects. Br J Clin Pharmacol, 61:280-8.

Fonseca V, Seftel A, Denne J, et al. 2004. Impact of diabetes mellitus on the severity of erectile dysfunction and response to treatment: analysis of data from tadalafil clinical trials. Diabetologia, 47:1914-23.

Govier F, Potempa AJ, Kaufman J, et al. 2003. A multicenter, randomized, double-blind, crossover study of patient preference for tadalafil $20 \mathrm{mg}$ or sildenafil citrate $50 \mathrm{mg}$ during initiation of treatment for erectile dysfunction. Clin Ther, 25:2709-23.

Gupta M, Kovar A, Meibohm B. 2005. The clinical pharmacokinetics of phosphodiesterase-5 inhibitors for erectile dysfunction. $J$ Clin Pharmacol, 45:987-1003.

Hanson-Divers C, Jackson SE, Lue TF, et al. 1998. Health outcomes variables important to patients in the treatment of erectile dysfunction. J Urol, 159:1541-7.

Hatzichristou D, Gambla M, Rubio-Aurioles E, et al. 2008. Efficacy of tadalafil once daily in men with diabetes mellitus and erectile dysfunction. Diabet Med, 25:138-46.

Hellstrom WJ, Overstreet JW, Yu A, et al. 2003. Tadalafil has no detrimental effect on human spermatogenesis or reproductive hormones. $J$ Urol, 170:887-91

Hurt KJ, Musicki B, Palese MA, et al. 2002. Akt-dependent phosphorylation of endothelial nitric-oxide synthase mediates penile erection. Proc Natl Acad Sci U S A, 99:4061-66.

ICOS. 2008. Tadalafil (Cialis) US prescribing information. Accessed June 25, 2008. URL: http://www.lilly.com/us/cialis-pi.pdf.

Incrocci L, Slagter C, Slob AK, et al. 2006. A randomized, double-blind, placebo-controlled, cross-over study to assess the efficacy of tadalafil (Cialis) in the treatment of erectile dysfunction following threedimensional conformal external-beam radiotherapy for prostatic carcinoma. Int J Radiat Oncol Biol Phys, 66:439-44.

Incrocci L, Slob AK, Hop WC. 2007. Tadalafil (Cialis) and erectile dysfunction after radiotherapy for prostate cancer: an open-label extension of a blinded trial. Urology, 70:1190-3.

Johannes CB, Araujo AB, Feldman HA, et al. 2000. Incidence of erectile dysfunction in men 40-69 years old: longitudinal results from the Massachusetts Male Aging Study. J Urol, 163:460-3.

Kaminetsky J. 2008. Epidemiology and pathophysiology of male sexual dysfunction. Int J Impot Res, 20:S3-10.

King SH, Hallock M, Strote J, et al. 2005. Tadalafil-associated priapism. Urology, 66:432.

Kloner RA. 2004. Cardiovascular effects of the 3 phosphodiesterase- 5 inhibitors approved for the treatment of erectile dysfunction. Circulation, 110:3149-55

Kloner RA, Hutter AM, Emmick JT. 2003a. Time course of the interaction between Tadalafil and Nitrates. J Am Coll Cardiol, 42:1885-60.
Kloner RA, Jackson G, Emmick JT, et al. 2004. Interaction between the phosphodiesterase 5 inhibitor, tadalafil and 2 alpha-blockers, doxazosin and tamsulosin in healthy normotensive men. J Urol, 172:1935-40.

Kloner RA, Jackson G, Hutter AM, et al. 2006. Cardiovascular safety update of Tadalafil: retrospective analysis of data from placebo-controlled and open-label clinical trials of Tadalafil with as needed, three timesper-week or once-a-day dosing. Am J Cardiol, 97:1778-84.

Kloner RA, Mitchell M, Emmick JT. 2003b. Cardiovascular effects of tadalafil. Am J Cardiol, 92:37M-46M.

Kloner RA, Mitchell M, Emmick JT. 2003c. Cardiovascular effects of tadalafil in patients on common antihypertensive therapies. $A m J$ Cardiol, 92:47M-57M.

Kostis JB, Jackson G, Rosen R, et al. 2005. Sexual dysfunction and cardiac risk (the Second Princeton Consensus Conference). Am J Cardiol, 96:313-21.

Kovanecz I, Rambhatla A, Ferrini MG, et al. 2008. Chronic daily tadalafil prevents the corporal fibrosis and veno-occlusive dysfunction that occurs after cavernosal nerve resection. BJU Int, 101:203-10.

Krane RJ. 1986. Sexual Function and Dysfunction. In Walsh, Gittes, Perlmutter, Stamey (ed). Campbell's Urology. 5th ed. Philadelphia: W.B. Saunders Company. Vol 1, p 731.

Lin CS, Xin ZC, Lin G et al. 2003. Phosphodiesterases as therapeutic targets. Urology, 61:685-91.

Lincoln TM, Cornwell TL. 1991. Towards an understanding of the mechanism of action of cyclic AMP and cyclic GMP in smooth muscle relaxation. Blood Vessels, 28:129-37.

Lue TF. 2000. Erectile dysfunction. $N$ Engl J Med, 342:1802-13.

McKinlay, JB. 2000. The worldwide prevalence and epidemiology of erectile dysfunction. Int J Impot Res, 12:S6-S11.

McMahon C. 2004. Efficacy and safety of daily tadalafil in men with erectile dysfunction previously unresponsive to on-demand tadalafil. $J$ Sex Med, 1:292-300.

McMahon C. 2005. Comparison of efficacy, safety, and tolerability of on-demand tadalafil and daily dosed tadalafil for the treatment of erectile dysfunction. J Sex Med, 2:415-25.

McVary KT, McKenna KE. 2004. The relationship between erectile dysfunction and lower urinary tract symptoms: epidemiological, clinical, and basic science evidence. Curr Urol Rep, 5:251-7.

McVary KT, Roehrborn CG, Kaminetsky JC, et al. 2007. Tadalafil relieves lower urinary tract symptoms secondary to benign prostatic hyperplasia. J Urol, 177:1401-7.

Menon M, Kaul S, Bhandari A, et al. 2005. Potency following robotic radical prostatectomy: a questionnaire based analysis of outcomes after conventional nerve sparing and prostatic fascia sparing techniques. J Urol, 174:2291-6.

Montorsi F, Brock G, Lee J, et al. 2008. Effect of Nightly versus On-Demand Vardenafil on Recovery of Erectile Function in Men Following Bilateral Nerve-Sparing Radical Prostatectomy. Eur Urol, Jul 9 [Epub ahead of print].

Montorsi F, McDermott TE, Morgan R, et al. 1999. Efficacy and safety of fixed-dose oral sildenafil in treatment of erectile dysfunction of various etiologies. Urology, 55:1011-8.

Montorsi F, Nathan HP, McCullough A, et al. 2004. Tadalafil in the treatment of erectile dysfunction following bilateral nerve sparing radical retropubic prostatectomy: a randomized, double-blind, placebo controlled trial. Urology, 172:1036-41. Erratum in: J Urol, 2005;173:664.

NIH Consensus Development Panel on Impotence. 1993. NIH Consensus Conference: impotence. JAMA, 270:83-90.

Padma-Nathan H, McCullough AR, Levine LA, et al. 2008. Randomized, double-blind, placebo-controlled study of postoperative nightly sildenafil citrate for the prevention of erectile dysfunction after bilateral nerve-sparing radical prostatectomy. Int J Impot Res, Jul 24 [Epub ahead of print]

Penson DF, Latini DM, Lubeck DP, et al. 2003. Do impotent men with diabetes have more severe erectile dysfunction and worse quality of life than the general population of impotent patients? Results from the Exploratory Comprehensive Evaluation of Erectile Dysfunction (ExCEED) database. Diabetes Care, 26:1093-9. 
Penson DF, McLerran D, Feng Z, et al. 2008. 5-year urinary and sexual outcomes after radical prostatectomy: results from the Prostate Cancer Outcomes Study. J Urol, 179:S40-4.

Porst H, Giuliano F, Glina S, et al. 2006. Evaluation of the efficacy and safety of once-a-day dosing of tadalafil $5 \mathrm{mg}$ and $10 \mathrm{mg}$ in the treatment of erectile dysfunction: results of a multicenter, randomized, double-blind, placebo-controlled trial. Eur Urol, 50:351-9.

Porst H, Padma-Nathan H, Giuliano F, et al. 2003. Efficacy of tadalafil for the treatment of erectile dysfunction at 24 and 36 hours after dosing: a randomized controlled trial. Urology, 62:121-5.

Porst H, Rajfer J, Casabé A, et al. 2008. Long-term safety and efficacy of tadalafil $5 \mathrm{mg}$ dosed once daily in men with erectile dysfunction. $J$ Sex Med, Jun 13 [Epub ahead of print].

Porst H, Rosen RC, Padma-Nathan H, et al. 2002. Tadalafil allows men with erectile dysfunction to have successful intercourse up to 36 hours postdose [abstract]. J Urol, 167:177.

Raina R, Pahlajani G, Agarwal A, et al. 2008. Early penile rehabilitation following radical prostatectomy: Cleveland clinic experience. Int $J$ Impot Res, 20:121-6.

Rajfer J, Aliotta PJ, Steidle CP, et al. 2007. Tadalafil dosed once a day in men with erectile dysfunction: a randomized, double-blind, placebocontrolled study in the US. Int J Impot Res, 19:95-103.

Rambhatla A, Kovanecz I, Ferrini M, et al. 2008. Rationale for phosphodiesterase 5 inhibitor use post-radical prostatectomy: experimental and clinical review. Int J Impot Res, 20:30-4.

Roehrborn CG, McVary KT, Elion-Mboussa A, et al. 2008. Tadalafil administered once daily for lower urinary tract symptoms secondary to benign prostatic hyperplasia: a dose finding study. $J$ Urol, 180:1228-34.

Rosen RC, Riley A, Wagner G, et al. 1997. The international index of erectile function (IIEF): a multidimensional scale for assessment of erectile dysfunction. Urology, 49:822-30.
Sáenz de Tejada I, Anglin G, Knight JR, et al. 2002. Effects of tadalafil on erectile dysfunction in men with diabetes. Diabetes Care, 25:2159-64.

Stanford JL, Feng J, Hamilton AS, et al. 2000. Urinary and sexual function after radical prostatectomy for clinically localized prostate cancer: the Prostate Cancer Outcomes Study. JAMA, 283:354-60.

Ströberg P, Murphy A, Costigan T. 2003. Switching patients with erectile dysfunction from sildenafil citrate to tadalafil: results of a European multicenter, open-label study of patient preference. Clin Ther, 25:2724-37.

Sutherland EW, Rall TW. 1958. Fractionation and characterization of a cyclic adenine ribonucleotide formed by tissue particles. $J$ Biol Chem, 232:1077-91.

Talcott JA, Rieker P, Propert KJ, et al. 1997. Patient-reported impotence and incontinence after nerve-sparing radical prostatectomy. $J$ Natl Cancer Inst, 89:1117-23.

Uckert S, Kuthe A, Jonas U, et al. 2001. Characterization and functional relevance of cyclic nucleotide phosphodiesterase isoenzymes of the human prostate. $J$ Urol, 166:2484-90.

Vignozzi L, Filippi S, Morelli A, et al. 2006. Effect of chronic tadalafil administration on penile hypoxia induced by cavernous neurotomy in the rat. $J$ Sex Med, 3:419-31.

von Keitz A, Rajfer J, Segal S, et al. 2004. A multicenter, randomized, double-blind, crossover study to evaluate patient preference between tadalafil and sildenafil. Eur Urol, 45:499-507.

Walsh PC, Lepor H, Eggleston JC. 1983. Radical prostatectomy with preservation of sexual function: anatomical and pathological considerations. Prostate, 4:473-85.

Walsh PC, Marschke P, Ricker D, et al. 2000. Patient-reported urinary continence and sexual function after anatomic radical prostatectomy. Urology, 55:58-61. 
